\title{
A produção social do conhecimento e as lições de Bourdieu para a Ciência da Informação
}

Knowledge Social production and Bourdieau's lessons to Information Science

\begin{abstract}
Marco Antônio de Almeida
Doutor em Ciências Sociais pela Universidade Estadual de Campinas - UNICAMP. Professor do Curso de Biblioteconomia e Ciência da Informação da Faculdade de Filosofia, Ciências e Letras de Ribeirão Preto da Universidade de São Paulo - FFCLRP/USP.

E-mail: $\underline{\text { marcoaa@ffclrp.usp.br }}$
\end{abstract}

\begin{abstract}
MARTELETO, Regina M.; PIMENTA, Ricardo M. (Org.) Pierre Bourdieu e a produção social da cultura, do conhecimento e da informação. Rio de Janeiro: Garamond, 2017.
\end{abstract}

LUCAS, Elaine R. O.; SILVEIRA, Murilo A. S. (Org.) A Ciência da Informação encontra Bourdieu. São Paulo: Recife: UFPE, 2017.

No ano em que se registram os quinze anos de sua morte, Pierre Bourdieu e seu legado permanecem mais vivos do que nunca. Suas reflexões são objetos de debate em diversos campos, para além da Sociologia e da Antropologia que inicialmente os abrigaram, atravessando fronteiras disciplinares e nacionais. No caso específico da Ciência da Informação brasileira, o lançamento de duas coletâneas, tendo seu pensamento como mote, dá conta dessa presença: Pierre Bourdieu e a produção social da cultura, do conhecimento e da informação, organizado por Regina M. Marteleto e Ricardo M. Pimenta, e A Ciência da Informação encontra Bourdieu, organizado por Elaine R. O. Lucas e Murilo A. S. Silveira.

Essa celebridade, no entanto, nem sempre caracterizou a trajetória do autor. As dificuldades da sintaxe particular de seus escritos foi um obstáculo considerável às suas traduções, bem como o caráter fortemente franco-centrado de seus escritos e referências, que passaram a se alargar a partir dos anos 80 . Essa década marca sua penetração no cenário mundial tendo como impulso, principalmente, a tradução, em 1984, de La Distinction (cujo original francês é de 1979). Sua popularidade mundial será reforçada pela publicação, na década de 90, das obras da coleção "Liber", textos "mais engajados" e críticos da globalização, vertidos para diversos idiomas. Desse modo, a acolhida de Bourdieu no estrangeiro será fortemente marcada pelo peso dos contextos e das tradições científicas. Dependendo do país ou do campo de recepção, ele será lido como sociólogo da educação ou da cultura, epistemólogo das Ciências Sociais, um intelectual francês pós-estruturalista ou um crítico engajado da globalização. 
O Brasil se encaixa de forma particular nesse cenário, talvez pela forte presença da tradição francesa na formação universitária do país, que propiciou uma circulação precursora de seu pensamento por aqui. Destacam-se as coletâneas pioneiras de seus trabalhos ainda nos anos 70, no campo da Sociologia, por Renato Ortiz e Sérgio Micelli, e a penetração do pensamento bourdieusiano no campo da Educação, especialmente a partir das leituras de $\mathbf{A}$ Reproduçãa, escrito em parceria com Jean-Claude Passeron. Apesar dos trabalhos pioneiros de Regina Marteleto, que já incorporavam a perspectiva do autor às questões do campo, no caso da Ciência da Informação brasileira a influência de Bourdieu é mais recente. Nesse sentido, aparentemente, a chave de leitura que tem possibilitado sua apropriação é a contribuição para se pensar aspectos sociais, culturais e políticos da produção e circulação do conhecimento, reforçando o paradigma social do campo.

Contribuição extremamente importante, sem dúvida, já que Bourdieu destaca-se, entre outras coisas, pelo rigor da investigação empírica acerca de diferentes domínios das práticas sociais, acompanhado de uma reflexão epistemológica igualmente crítica no que tange aos objetos de estudo. Assim, a adoção da "objetivação participante", entendida como procedimento de reflexividade dos instrumentos de pesquisa e do próprio pesquisador, implica numa verdadeira revolução no entendimento das relações entre o conhecedor e o conhecimento, desfazendo tanto as ilusões de um objetivismo-positivista, assim como análises embasadas por um subjetivismo que se apropria simploriamente do cognitivismo.

Este rigor em relação à pesquisa e à reflexão se torna ainda mais fundamental na atual conjuntura histórica em que nos situamos. Um momento em que os laços sociais e os produtos culturais estão imersos em fluxos globalizados de comunicação e informação, reconfigurando novas possibilidades e formas de leitura, aprendizagem e interação. As novas mídias, redes e plataformas digitais estão redefinindo as formas de produção, acesso e apropriação do conhecimento, e, portanto, modificando as formas pelas quais os capitais sociais, culturais e informacionais são construídos pelos sujeitos - individuais e coletivos. Nesse sentido, uma abordagem socioantropológica do conhecimento revela-se estratégica para a compreensão dos fenômenos que a Ciência da Informação busca compreender, tornando prioritário refletir acerca do pensamento de um autor que esteve sempre com o olhar atento para os processos de dominação simbólica e de diferenciação social.

Trata-se, sem dúvida, de um pensamento polêmico, politizado, comprometido, que não é consensual - ou seja, que não deixa ninguém indiferente. Assim, muitos dos diálogos e leituras 
propostas nessas duas coletâneas de estudiosos do campo informacional e de campos disciplinares afins procuram ir além do pensamento bourdieusiano, postulando um esforço teórico-metodológico auto-reflexivo que seria aprovado pelo autor. Do mesmo modo, esse conjunto de textos assinala a pujança e a atualidade do pensamento de Bourdieu para refletir sobre diversos aspectos que compõem nossa sociedade perpassada pelos fluxos de informação e comunicação. Conceitos consagrados como os de "habitus", "campo", "capital simbólico", "distinção" são empregados em discussões que refletem tanto sobre os paradigmas e concepções dos estudos informacionais, como também sobre fenômenos relacionados, como as redes sociotécnicas, a educação, as formas de organização da ciência, as políticas estatais, os públicos das instituições culturais, entre outras.

Os textos reunidos em Pierre Bourdieu e a produção social da cultura, do conhecimento e da informação possuem uma perspectiva bastante abrangente, procurando mapear os conceitos presentes na obra do autor. Um mapeamento com viés fortemente interdisciplinar, caracterizado por um trânsito de ideias entre pesquisadores de diversas formações, instituições e vertentes, reunidos em 16 artigos assinados por 22 autores. Os artigos assumem tanto um perfil mais teórico como também apresentam a sistematização de produtos e resultados de pesquisas, que sinalizam possibilidades abertas para a Ciência da Informação para leituras e apropriações do pensamento bourdieusiano. A maior parte dos textos é produzida por pesquisadores e estudantes vinculados ao Programa de Pós-Graduação em Ciência da Informação (PPGCI) do Instituto Brasileiro de Informação em Ciência e Tecnologia (IBICT) em convênio com a Universidade Federal do Rio de Janeiro (UFRJ), onde se estabeleceu, desde os anos 80, um núcleo percursor na absorção do pensamento de Bourdieu.

O livro está estruturado em três partes que abordam, respectivamente, o campo informacional propriamente dito, o campo científico e, por último, transposições específicas do pensamento bourdieusiano a contextos e questões empíricas. A primeira parte, "Bourdieu e as teorias implicadas no conhecimento do campo informacional" ocupa-se dos intercruzamentos e apropriações da teoria do autor por parte da Ciência da informação - sua epistemologia, seus objetos de estudo e o diálogo com outros autores. Na segunda parte, "Bourdieu, a informação e o campo científico", a abordagem crítica do autor em relação ao campo científico é explorada no intuito de analisar as estruturas da ciência e da produção do conhecimento, particularmente em relação ao campo da Ciência da Informação. Finalmente, em "Bourdieu e a diversidade das práticas e processos culturais", terceira e última parte da coletânea, são reunidos artigos que abordam diferentes universos empíricos, convergindo com a perspectiva do autor em relação 
aos riscos da reificação teórica, evitável pela aplicabilidade dos conceitos aos contextos analisados.

Alguns dos autores presentes na coletânea anterior também comparecem na obra $\mathbf{A}$ Ciência da Informação encontra Bourdieu, mas o espectro de pertencimento institucional dos autores dos trabalhos é maior, perpassando diversas universidades e instituições, dando, já por essa variedade, uma boa amostra na ampla penetração contemporânea do pensamento de Bourdieu no campo da Ciência da Informação brasileira. A partir da observação de discussões empreendidas no campo da Ciência da Informação em diversos contextos acadêmicos colóquios, encontros, defesas de teses e dissertações, palestras - os organizadores decidiram por uma coletânea em torno do autor, com o objetivo de ampliar e verticalizar os debates e reflexões sobre as pesquisas realizadas no país. A decisão que culminou na escolha se deu pelo fato dos organizadores e de outros importantes pesquisadores do campo compartilharem as mesmas referências sobre este autor. Em conversas nos eventos ou nas leituras correntes e retrospectivas da literatura, observou-se que o repertório teórico e metodológico produzido por Pierre Bourdieu permanece atual, crítico, fundamentado em outros importantes repertórios e amplamente sintonizado com os compromissos sociais e culturais assumidos pela Ciência da Informação.

Também organizada em três partes, a coletânea reúne 19 artigos de 27 autores. Na primeira parte do livro, denominada de "Dimensões teóricas e metodológicas", nove artigos buscam articular contribuições teóricas e propostas metodológicas de Bourdieu para a área de Ciência da Informação. Os textos estão voltados para os processos de produção, organização, mediação e comunicação da informação, com enfoque em aspectos históricos, filosóficos, epistemológicos, entre outros. A segunda parte da obra, "Dimensões Aplicadas", contempla seis estudos analíticos que se baseiam nas propostas teóricas e metodológicas estabelecidas por Bourdieu. Esses textos buscam analisar as estruturas sociais e cognitivas que configuram as dinâmicas específicas dos campos da Ciência da Informação e da Arquivologia, consolidadas em instrumentais teóricos e metodológicos próprios, interconectando-as às ideias do autor. A última seção do livro, "Dimensões comparativas", apresenta quatro artigos que mapeiam relações e estabelecem diálogos e distinções entre Pierre Bourdieu e outros importantes autores e intelectuais, como Merton, Kuhn, Marx, Lukács e Zubiri, refletindo em como elas podem ser apropriadas e incorporadas nos estudos de informação com enfoques epistemológicos, políticos, históricos e éticos. 
O lançamento quase simultâneo dessas duas coletâneas acaba por ser não só uma forma de homenagem aos quinze anos de morte de Pierre Bourdieu, realçando a importância de seu legado intelectual, como também reafirma a demarcação da dimensão social da Ciência da Informação como campo científico consolidado pertencente ao conjunto de ciências sociais aplicadas e a seu espectro de reflexões, teorias e métodos.

Resenha enviada em 30 ago. 2017 